\title{
Canadian Service Providers' Perceptions of Barriers and Support Gaps in Housing and Mental Health
}

\author{
Nick Kerman \\ University of Ottawa \\ Reena Sirohi and Susan Eckerle Curwood \\ Centre for Addiction and Mental Health \\ John Trainor \\ Ontario Mental Health Foundation
}

\begin{abstract}
People experiencing mental illness and homelessness face numerous barriers to becoming housed. Service providers who work with this population also encounter challenges to meeting service users' needs, yet their perspectives have been only minimally studied. Using survey data from a pan-Canadian study, this article explores the barriers and facilitators to fostering lasting change in housing and mental health according to 96 housing providers and 186 community-based mental health service providers. Findings show that the perspectives of mental health service providers are largely consistent with those of housing providers, and identify a range of support gaps and barriers.
\end{abstract}

Keywords: housing, mental illness, community mental health services, unmet support needs, service provision

\section{RÉSUMÉ}

Les sans-abris ayant des maladies mentales font face à plusieurs défis dans la recherche d'un logement. De leur côté, les gens qui travaillent dans le domaine ont de la difficulté à combler les besoins de ces

Nick Kerman, School of Psychology, University of Ottawa, Ottawa, Ontario; Reena Sirohi, Social Determinants of Health Service, Centre for Addiction and Mental Health, Toronto, Ontario; Susan Eckerle Curwood, Provincial System Support Program, Centre for Addiction and Mental Health, Toronto, Ontario; John Trainor, Ontario Mental Health Foundation, Toronto, Ontario.

This research was supported by a grant from the Mental Health Commission of Canada. The authors wish to thank John Sylvestre for his thoughtful comments on an early draft of the manuscript and Danielle Petricone-Westwood for providing translation assistance.

Correspondence concerning this article should be addressed to Nick Kerman, School of Psychology, University of Ottawa, Ottawa, Ontario, Canada, K1N 6N5. Email: nkerm094@uottawa.ca 
usagers, mais leurs points de vue sur ces lacunes sont peu étudiés. Dans cet article, les auteurs examinent les obstacles qui freinent le changement à long terme en matière de logement pour les personnes ayant des maladies mentales et explorent des moyens qui permettraient de faciliter ce changement. Pour ce faire, ils utilisent les données d'une étude transcanadienne faite auprès de 96 fournisseurs de logement et de 186 travailleurs en santé mentale communautaire. Les résultats montrent que les points de vue des travailleurs en santé mentale et ceux des fournisseurs de logement se rejoignent. Les auteurs définissent ainsi plusieurs lacunes et obstacles qui existent dans ce domaine.

Mots clés : logement, maladie mentale, services communautaires de santé mentale, besoins non satisfaits, prestation de services.

Housing is a foundation for mental health recovery. Yet, homelessness and inadequate housing continue to be harsh realities faced by many Canadians with mental illness (Gaetz, Gulliver, \& Richter, 2014). As a result of their homelessness, people are at greater risk of experiencing deteriorating mental health (Daiski, 2007), developing chronic medical conditions (Hwang, 2001), being physically and sexually assaulted (Kushel, Evans, Perry, Robertson, \& Moss, 2003), and dying younger (Hwang, 2000). Homelessness not only affects those who experience it but also the broader service systems as costs and inefficiencies. For example, people experiencing mental illness and homelessness have been found to access crisis-type resources to meet their needs, such as emergency departments for health care, homeless shelters for housing, and meal programs for food (Folsom et al., 2005; Hwang et al., 2005). Many of these services are not only costly but may also inadequately meet the needs of those individuals who use them. The provision of housing is a method of intervention that helps people exit homelessness and reduces the burden on limited resources by affecting people's patterns of service use. For instance, when people with mental illness become housed, they show greater use of outpatient clinics, and less reliance on emergency departments and inpatient hospitalization (Gilmer, Manning, \& Ettner, 2009; Gilmer, Stefancic, Ettner, Manning, \& Tsemberis, 2010; Rog et al., 2014). Despite the success of multiple interventions that stably house people with mental illness and reduce the burden on service systems (Nelson, Aubry, \& Lafrance, 2007; Woodhall-Melnik \& Dunn, 2016), there are numerous systemic barriers to people with mental illness exiting homelessness.

One of the most notable systemic barriers is the lack of affordable housing. In Canada, the climbing rates of homelessness over the past 25 years are closely tied with decreased investments in social housing by the Government of Canada (Gaetz et al., 2014). With wait-lists for affordable housing continuing to grow across many regions in Canada (Mental Health Commission of Canada [MHCC], 2013a), this shortage can be characterized as a worsening crisis. Complicating matters further for those with mental illness is that housing on its own may be insufficient for becoming and remaining housed - additional treatment and support are needed (Nelson, 2010). For example, people with mental illness identify a range of supports as essential for becoming and staying housed, such as income supports, programs to enhance food security, mental health services, employment supports, and life-skills training (Kerman, Eckerle Curwood, Sirohi, \& Trainor, 2013). Without the appropriate supports, housing may be insufficient to reduce people's reliance on emergency services or facilitate stability of tenure. 
A second systemic issue is fragmentation and lack of coordination within the mental health and housing service sectors. Because of the traditional separation between the two sectors, people experiencing mental illness and homelessness are often forced to navigate discrete service systems to meet their needs. The complexity of systems acts as another barrier to service accessibility, contributing to the unmet support needs that are common among this population (e.g., Baggett, O’Connell, Singer, \& Rigotti, 2010). Service providers can play a key role in bridging the gap between the mental health and housing sectors but may also encounter barriers to doing so. Given the importance of service linkages within fragmented support systems, it is necessary to identify and address the challenges faced by service providers as a way of enabling people with mental illness to get the housing and support they require.

Internationally, studies on the perspectives of service providers who work with populations experiencing mental illness and homelessness are scarce, with even less research having been conducted in Canada. Although findings from work done internationally may not fully generalize to Canadian service systems, this research may point to the types of barriers that service providers in Canada will encounter in their work. A qualitative study by Canavan et al. (2012) examined the perspectives of mental health service providers who work with people experiencing homelessness in 14 European capital cities to identify barriers to care. Results showed a range of systemic challenges, including lack of clarity about the roles of different service agencies; low levels of collaboration between mental health, social, and homeless services; and incapacity of the housing sector to meet the level of need. To overcome these barriers, service providers called for greater collaboration between service agencies, and the adoption of more comprehensive approaches to treatment and care that encompass housing and employment needs.

Systemic barriers to helping to address the unmet needs of people experiencing homelessness have also been found in studies of providers working in US contexts. For example, in a small qualitative study of shelter and health service providers, shelter staff identified lack of knowledge of resources and long waiting lists for specialty care as key systemic barriers to accessing health care or addressing unmet needs (Hauff \& Secor-Turner, 2014). Similarly, health service providers pointed to long waiting lists, particularly for psychiatric care, but also encountered difficulties with coordination of care. Both service provider groups agreed that there was a need for more affordable housing, housing first models, trauma-informed care, and shelter-based case management. Another qualitative study examined service providers' perspectives of the facilitators and barriers to helping people experiencing homelessness become housed (Meschede, 2011). Common facilitators included coordination with other programs that provide housing, as well as within providers' own systems of care. Strong relationships between service providers and users were another factor cited as facilitating access to housing. In contrast, lack of referral options, unskilled staff, and service eligibility rules were identified as barriers.

A related stream of research, albeit a limited one, has examined the perspectives of landlords that serve people with mental illness and other vulnerable populations. These studies highlight the challenges faced by housing providers related to problematic behaviours of tenants and collaboration with mental health services. In turn, these barriers can impede landlords' willingness and abilities to help people remain stably housed. For example, a qualitative study of private market housing landlords in Sweden found that they encountered a range of behavioural challenges, including threats of violence and arson, with tenants who have serious mental illnesses (Bengtsson-Tops \& Hansson, 2014). To address these problems, landlords recognized 
that they needed help but felt abandoned and neglected by the mental health system, which caused them to negatively evaluate their own work. Landlords serving housing first tenants have also reported similar issues, including drug use and dealing, conflict with other residents, involvement with police, prostitution, and arson (Aubry et al., 2015a; MacLeod, Nelson, O’Campo, \& Jeyaratnam, 2015). In turn, these problems were seen as causing worry among housing staff, other tenants to move out, devaluation of the reputation of apartment buildings, and conflicts between landlords and clinical teams. However, when communication and cooperation between landlords and clinical teams were perceived to be positive, these relationships were seen as supportive of people's tenancies. Accordingly, relationships between service providers can be either detrimental to, or supportive of, the housing stability of people with mental illness.

Although the evidence base needs to be strengthened, it is evident that service providers face numerous barriers that interfere with their ability to better meet the needs of people experiencing homelessness, including those with mental illness. However, given that the studies to date have utilized exclusively qualitative designs, it is unclear how pervasive these problems are. Moreover, scarce attention has been paid to the unique challenges faced by different types of providers. To improve service delivery and bring about lasting change in community mental health systems, a greater understanding is needed of service providers' perceptions of the unmet mental health and housing support needs of people with mental illness, as well as the barriers and facilitators to addressing those needs.

Using survey data drawn from a pan-Canadian research project on housing and supports for people with mental illness (MHCC, 2013a), this study will explore the unmet support needs, barriers, and facilitators to helping this population to become and stay housed, as seen by service providers. The perspectives of housing and community-based mental health service providers will be examined, with discussion of the similarities and differences between their views. The larger project from which data are being analyzed was approved by a hospital research ethics board.

\section{METHOD}

\section{Sample}

The study sample comprises 186 community-based mental health service providers and 96 housing providers from across Canada. Mental health service providers were any individuals who worked for a community organization that offers mental health services. Housing providers included those who worked for agencies that have housing and support services specifically for people with mental illness, as well as ones that offer generic housing (i.e., no support services and not designated only for people with mental illness). Service providers whose agencies provided housing units and mental health services completed the survey for housing providers. Informed consent was provided by all participants prior to commencing the survey.

\section{Surveys}

Separate surveys were developed for each stakeholder group (community-based mental health service providers and housing providers) to understand the specific issues related to housing and supports faced by different communities across Canada. The surveys were developed through consultations with the project's 13 provincial and territorial advisory groups, national advisory group, and project steering committee, which 
comprised a mix of more than 200 researchers, service providers, policy makers, and people with lived experience of mental illness. Surveys underwent pilot testing over a three-week period after which revisions were made according to received feedback. Surveys were made available online or in hardcopy format, and in English and French.

Surveys for housing and community-based mental health service providers were composed primarily of list-type questions in which participants were asked to check all of the items that apply. This study will report upon findings from three domains of the survey: unmet support needs of service users (50 items), barriers to meeting housing and support-related needs ( 22 items), and factors that facilitate access to mental health and housing services (15 items). In addition, information is presented to describe the sample from the perspectives of geographic location (province/territory), size of agency (assessed subjectively in relation to other agencies in the community), primary community served (urban or rural), and proportion of services dedicated to people with mental illness. These sections of the surveys were identical for housing and mental health service providers.

Chain referral sampling was used to reach service providers from across the country. The approach was chosen given the existence of the project's advisory groups and steering committee, which facilitated the dissemination of the surveys within their extensive networks. In addition to distribution through the advisory groups, survey links and printable PDFs were also sent to mental health and housing community agencies and networks. For more detail about the sampling method used, see MHCC (2013b).

\section{Data Analysis}

Data were analyzed using descriptive statistics conducted in SPSS 23. Comparisons between the service providers' perspectives were completed using chi-square analyses. Due to the multiple comparisons, the Benjamini-Hochberg method of controlling the false discovery rate was used to calculate corrected levels of significance (Benjamini \& Hochberg, 1995).

\section{RESULTS}

\section{Description of Sample}

All provinces and territories except Nunavut were represented in the sample (see Table 1). In addition, four service providers $(1.4 \%)$ worked for agencies with national mandates. Of note, proportional to the provinces' populations, Quebec was very underrepresented and Ontario slightly overrepresented in the sample. Data were missing for one participant $(0.4 \%)$. The size of providers' agencies, communities served, and proportion of services dedicated to people with mental illness are listed in Table 1.

\section{Unmet Support Needs}

A list of the most commonly reported unmet support needs according to mental health and housing service providers is provided in Table 2. Of them, three unmet needs were identified by more than half of the overall sample (24-hour onsite supports, crisis and respite beds, and integrated mental health and housing 
services). Chi-square analyses were conducted for each support need by provider type, with all tests producing non-significant findings given the statistical adjustments.

\section{Table 1}

\section{Agency Size, and Communities and Clients Served by Provider Type}

\begin{tabular}{llll}
\hline Province & $\begin{array}{l}\text { All Service Providers } \\
(N=282)\end{array}$ & $\begin{array}{l}\text { Mental Health Service } \\
\text { Providers } \\
(n=186)\end{array}$ & $\begin{array}{l}\text { Housing Providers } \\
(n=96)\end{array}$ \\
\hline Agency Size & $78(27.7 \%)$ & $55(29.6 \%)$ & $23(24.0 \%)$ \\
Large & $100(35.5 \%)$ & $76(40.8 \%)$ & $24(25.0 \%)$ \\
Medium & $88(31.2 \%)$ & $51(27.4 \%)$ & $37(38.5 \%)$ \\
Size & & & \\
Province & $11(3.9 \%)$ & $7(3.8 \%)$ & $4(4.2 \%)$ \\
Alberta & $51(18.1 \%)$ & $34(18.3 \%)$ & $17(17.7 \%)$ \\
British Columbia & $15(5.3 \%)$ & $11(5.9 \%)$ & $4(4.2 \%)$ \\
Manitoba & $6(2.1 \%)$ & $4(2.2 \%)$ & $2(2.1 \%)$ \\
New Brunswick & $26(9.2 \%)$ & $22(11.8 \%)$ & $4(4.2 \%)$ \\
Newfoundland and Labrador & $2(0.7 \%)$ & $1(0.5 \%)$ & $1(1.0 \%)$ \\
Northwest Territories & $12(4.3 \%)$ & $10(5.4 \%)$ & $2(2.1 \%)$ \\
Nova Scotia & $139(49.3 \%)$ & $86(46.2 \%)$ & $53(55.2 \%)$ \\
Ontario & $2(0.7 \%)$ & 0 & $2(2.1 \%)$ \\
Prince Edward Island & $6(2.1 \%)$ & $4(2.2 \%)$ & $2(2.1 \%)$ \\
Quebec & $6(2.1 \%)$ & $5(2.7 \%)$ & $1(1.0 \%)$ \\
Saskatchewan & $1(0.4 \%)$ & $1(0.5 \%)$ & 0 \\
Yukon & $4(1.4 \%)$ & $1(0.5 \%)$ & $3(3.1 \%)$ \\
National & & $88(47.3 \%)$ & $17(17 \%)$ \\
Community Served & $73(25.9 \%)$ & $55(29.6 \%)$ & $78(81.3 \%)$ \\
Rural & $209(74.1 \%)$ & $131(70.4 \%)$ & $49(51.0 \%)$ \\
Urban & $138(48.9 \%)$ & $89(47.8 \%)$ & $26(27.1 \%)$ \\
Dedicated Services & $24(8.5 \%)$ & $7(3.8 \%)$ & $17 \%)$ \\
All & & & \\
Some & None & & \\
\hline
\end{tabular}

Note. Nunavut was not represented in the sample. Urban = metropolitan cities of 50,000 people or more, or areas adjacent to a metropolitan city. Rural $=$ areas with populations of less than 50,000 and no neighbouring metropolitan city. 


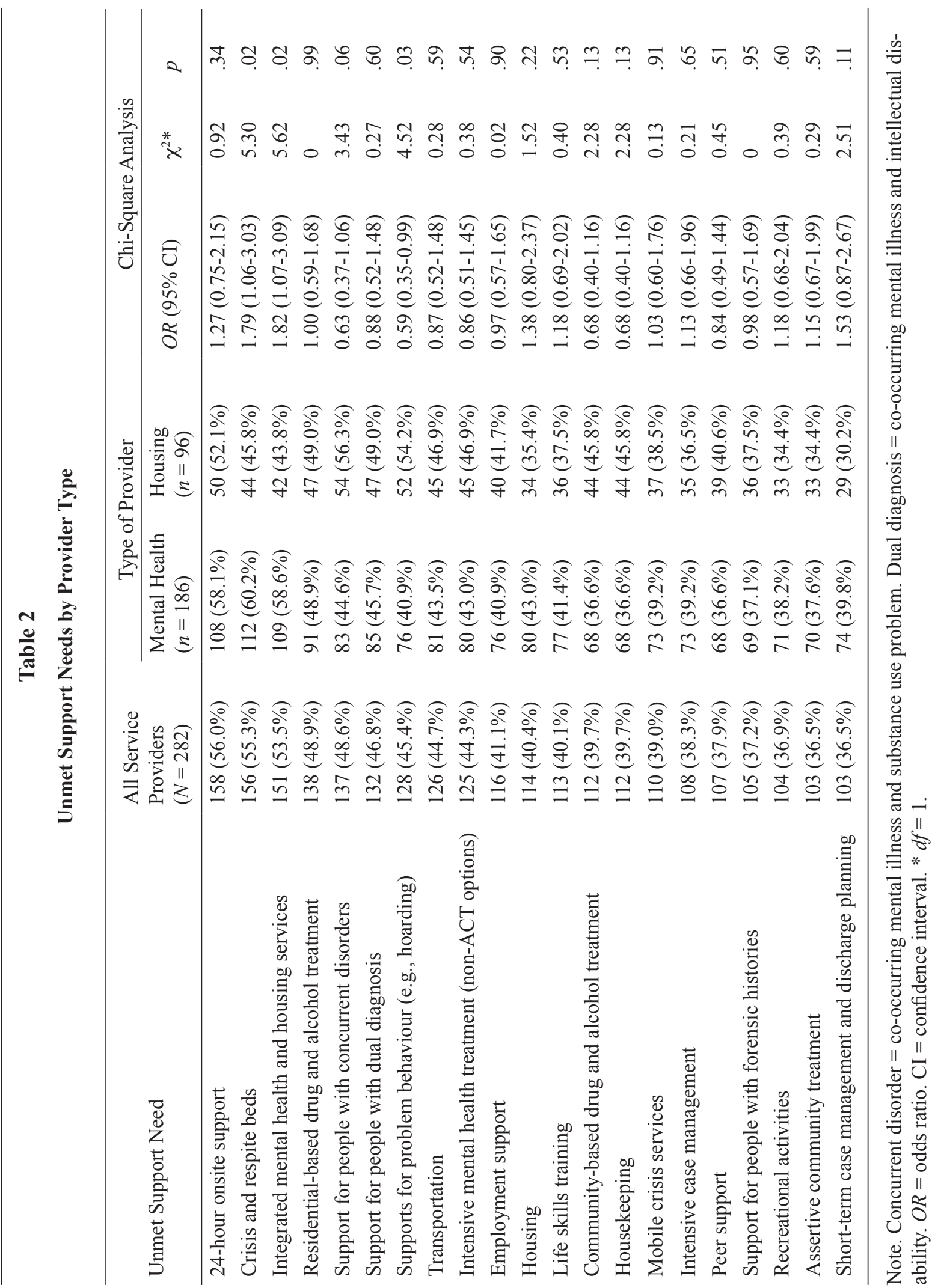




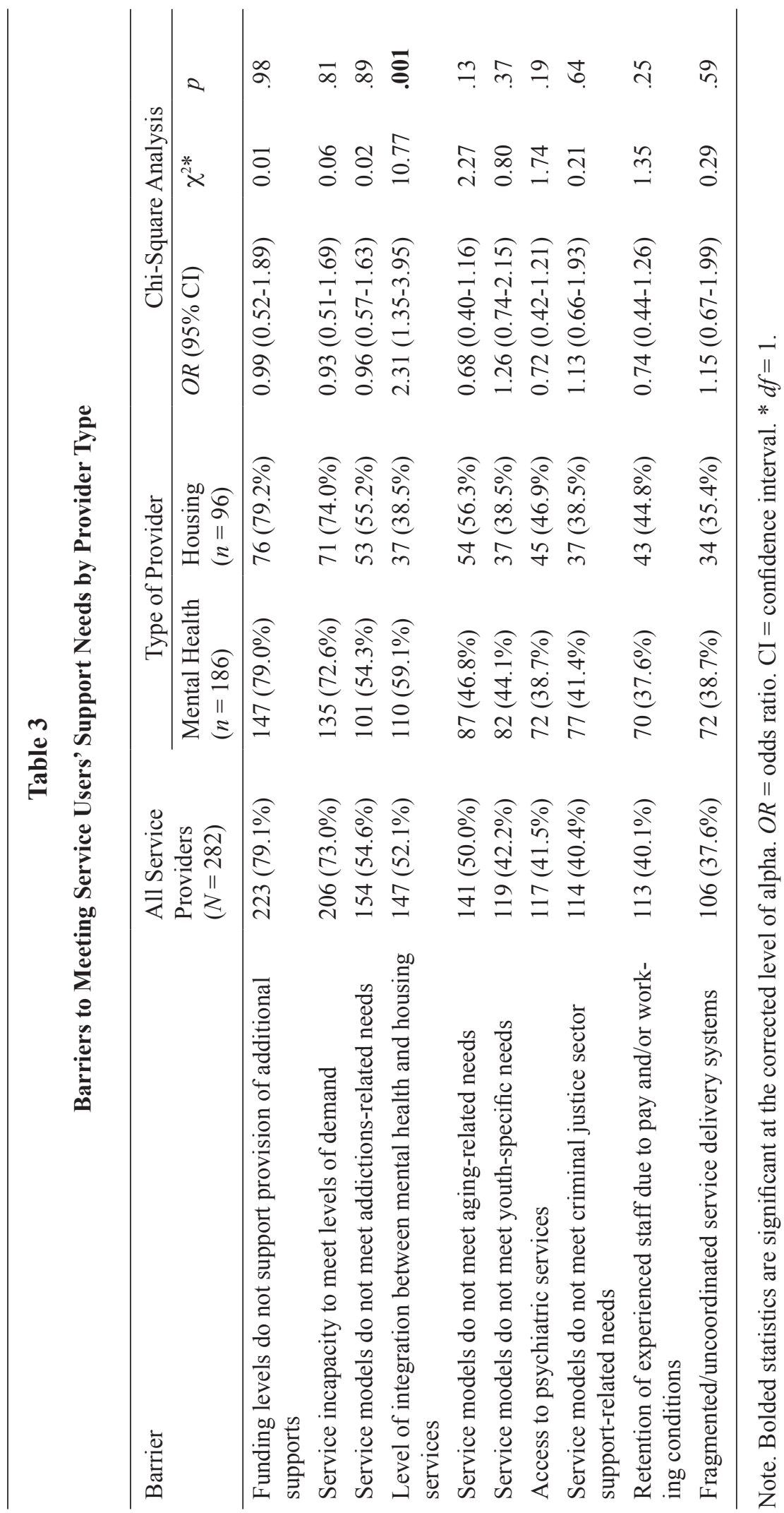




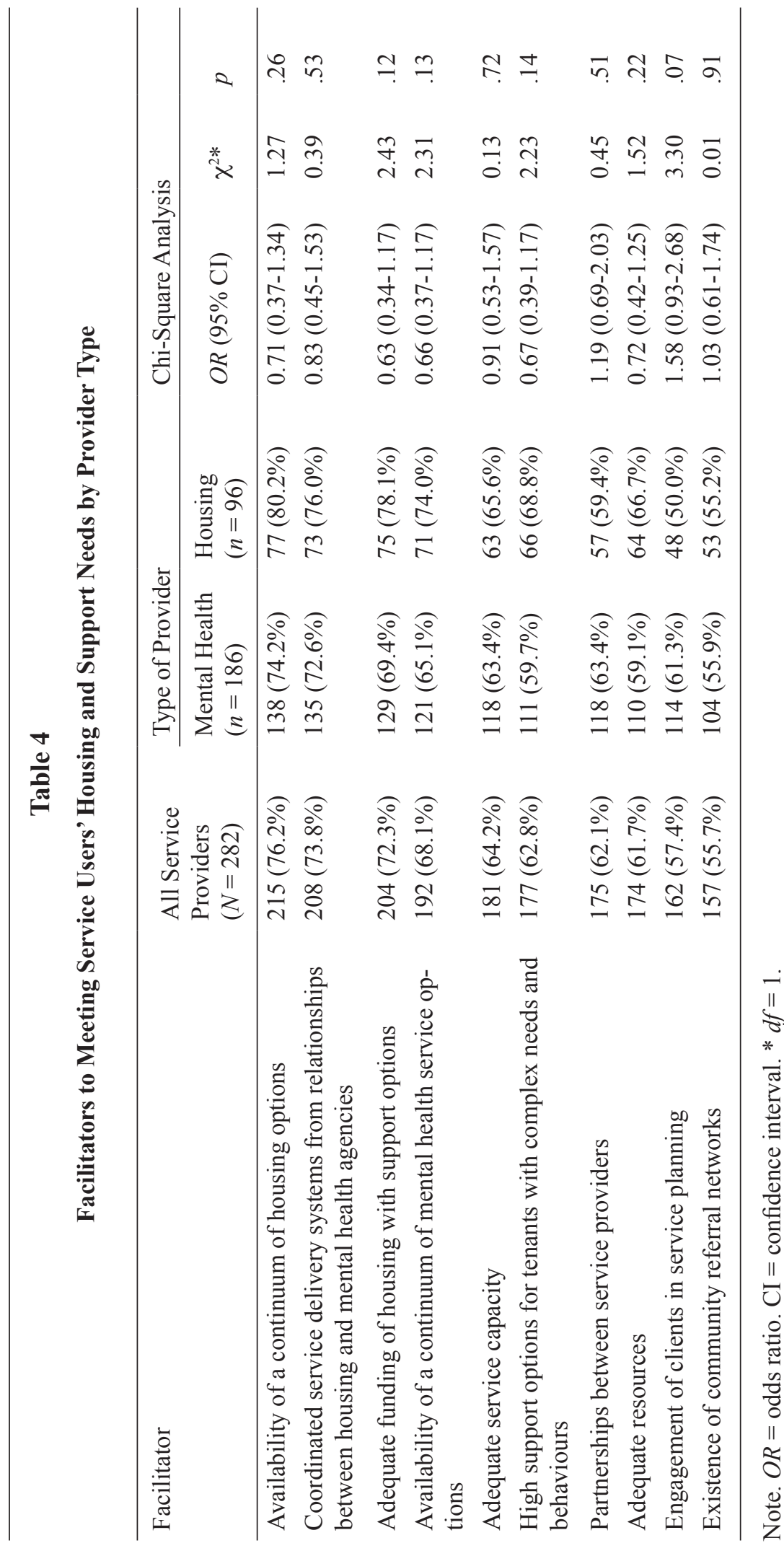




\section{Barriers and Facilitators to Housing and Supports}

An array of factors prevented service providers from meeting the housing needs of their clients; see Table 3 for the most commonly reported barriers. Similar to unmet support needs, the service provider groups seldom differed on the barriers they faced. However, mental health service providers were significantly more likely to report levels of integration between mental health and housing services to be a barrier than were housing providers $(O R=2.31,95 \% \mathrm{CI}=1.35-3.95, p=.001)$.

The most commonly identified facilitators of meeting people's housing and mental health support needs were related to resources and partnerships (see Table 4). Specifically, the existence of an adequate supply of services, greater diversity in available services (i.e., continuum of support options), and more collaboration between service agencies and providers were key factors to meeting the housing and support needs of people with mental illness. No significant differences were found between providers.

\section{DISCUSSION}

The perspectives of mental health service providers are consistent with those of housing providers on the unmet support needs of people with mental illness across Canada. Moreover, the two groups of service providers largely share the same views on the barriers and facilitators to meeting service users' housing and support needs, again demonstrating a high level of uniformity in perspectives of areas where more work is needed. The findings also suggest pervasive challenges faced by service providers in the delivery of mental health and housing support to people with mental illness. Perhaps most notable is providers' perspectives on systemic incapacity to do more - a challenge intensified within mental health systems across Canada where shares of healthcare funding have declined for decades. As Lurie and Goldbloom (2015) point out, in Ontario, less than $7 \%$ of provincial healthcare spending is allocated to mental health, which is almost a $40 \%$ decrease since 1979 when mental health received 11.3\%. Further, with much of the funds being spent on hospital-based care, community mental health services, which are essential to helping people experiencing mental illness and homelessness to become housed, are stretched even thinner. This perspective was affirmed by many providers in this study, as roughly three-quarters identified demand for services as outweighing supply and funding levels not accommodating additional supports. The former, for example, is evident given the affordable housing stock shortages across Canada. As for the incapacity to provide additional supports due to funding levels, this is particularly problematic given that permanent, affordable housing on its own is often insufficient to meet the needs of many people with mental illness - a perspective that appears to be shared by the service providers in this study. Relatedly, housing and supports were identified as prominent facilitators in the form of coordinated mental health and housing service delivery systems, high support housing stock, and organizational partnerships.

Overall, service providers see a need for more safe, affordable housing with supports for people with mental illness. This is a perspective that strongly aligns with recommendations from the MHCC's (2012) national mental health strategy, which identified access to housing with supports as a key priority. However, there may be some divergence in the types of support that are thought to be most needed. According to service providers, more housing options that offer around-the-clock onsite support were reported as the most frequent unmet support need. This need is partially incongruent with the prioritization of housing first across many 
regions in the country. Given that the housing first model, as developed by Pathways to Housing, involves scatter-site apartments with 24-hour support that is unconnected to the housing (i.e., offsite supports that can be delivered in the home environment as needed; Tsemberis, 2010), it may provide a level of support that is lower or a structure of service delivery that is different from what service providers perceive to be lacking. Nevertheless, given the success of the housing first model and its continued implementation across the country, the question is what proportion of housing stock in communities ought to be housing first and how much housing with even greater support is needed. Despite the especially positive findings that housing first has had in Canada, there is still a minority - roughly 25\% of individuals - who do not achieve favourable housing outcomes via the model (Aubry et al., 2015b, 2016). Although the reasons why some people experience difficulties are not fully understood, it is crucially important to consider that housing first may not be a one-size-fits-all model in the development and implementation of future housing for people with mental illness. Integrating housing first principles and values (e.g., tenancy rights, service choice, harm reduction, privacy) into other high support housing models, such as ones that offer onsite support, may enhance the coordination and functionality of mental health and housing systems by addressing the concerns of service providers while also providing services that incorporate aspects of evidence-based practices.

The location of housing also plays an important role in promoting or hindering housing stability. Access to services is often a key consideration in the development of mental health housing programs, with locations prioritized that enable tenants to walk or take public transit to grocery stores, coffee shops, libraries, day programs, and health and community services (Zippay \& Thompson, 2007). In this study, almost half of service providers perceived transportation to be an unmet support need. Although a range of factors, including affordability, may have influenced providers' views on transportation being an unmet support need, the finding raises concern about the accessibility of community services to housing first tenants. With tight housing markets and a lack of affordable options in many cities across Canada, there is risk that people with mental illness may be displaced from their home communities or be forced to reside in areas that are poorly resourced. Moreover, given that there may be a positive relationship between people's mobility in the community and their mental health recovery (Townley, Kloos, \& Wright, 2009), developing and providing housing in isolated areas without nearby services may undermine people's mental health and their housing stability.

\section{Serving Complex Needs}

Difficulties faced by providers in serving people experiencing mental illness and homelessness can be compounded further by the population's vulnerability to, and presentation of, other health and behavioural challenges. Many providers reported that the people they serve had unmet needs related to their substance use; intellectual disabilities; and problematic behaviours, such as hoarding. With respect to the barriers that service providers had encountered, issues pertaining to people with complex needs were again present, as service models were frequently identified as not meeting the addictions-related, aging-related, youth-specific, and criminal justice sector support-related needs of clients. Each subpopulation is associated with unique challenges related to service provision. For example, for people experiencing homelessness who also have a mental illness and an intellectual disability, as Lougheed and Farrell (2013) noted, balancing protection from abuse and neglect with empowerment and choice is essential but not always an easy task. This is due, 
in part, to organizational challenges with accurately identifying those who are intellectually disabled, and assessing people's abilities to cope and stay safe, as well as the mandates of the agencies that serve this group.

Individuals with co-occurring mental illness and substance use problems are another subpopulation for whom there are unique challenges in service provision. Although housing outcomes using best-practices are positive for this group (e.g., Palepu, Patterson, Moniruzzaman, Frankish, \& Somers, 2013), service providers may have to manage safety concerns and sudden behaviours (e.g., associations with drug dealers, disappearances following relapse); longer trajectories toward housing stability, trust of providers, and recovery; and locating substance use treatment services in resource-poor communities (Foster, LeFauve, Kresky-Wolff, \& Rickards, 2010). The additional challenges that service providers face in working with groups that have more complex needs require greater attention. To increase service capacity, further training for direct service providers is needed, as is additional funding allocation to mental health and housing agencies that serve people with complex needs. In particular, the latter is key within health systems that fund and implement mental health and addictions services separately. Further development of programs that have broader service offerings will begin to reduce challenges faced by providers who work with people with complex needs and facilitate more timely access to treatment and care.

\section{Mental Health-Housing Partnerships}

The integration of mental health and housing services was cited by service providers as a common unmet support need and barrier to effective service provision. Moreover, partnerships and relationships between service agencies were identified as prominent facilitators to care, highlighting the essential role of collaboration in an underfunded mental health housing system. Although service providers perceive partnerships between housing and mental health agencies as having benefits for their work with people with mental illness, they are also a way of increasing the stock of safe, affordable housing with supports. Through service collaborations, existing housing programs that do not offer support services are remodelled into ones that can offer tenants the mental health care they need to stay stably housed. This transformative work is already underway in many regions across Canada, as there are numerous examples of innovative partnership models between mental health and housing agencies (see MHCC, 2013b; Nichols \& Doberstein, 2016). However, research on such collaborations is scarce (Kloos et al., 2014) and represents a key gap that should be prioritized in future work. In doing so, key areas of study may include operationalization and measurement of service integration, ways in which different mental health-housing partnership models facilitate service integration, and innovative approaches to transforming existing mental health and housing resources to better meet the needs of people experiencing homelessness and mental illness. Consideration should also be given to how partnerships between housing and mental health service providers can reduce stigmatizing and not-in-my-backyard attitudes held by some landlords or within communities. The further development and evaluation of partnerships within, and between, agencies will reduce burden and barriers faced by direct service providers in addressing the unmet support needs of people with mental illness, as well as foster progress toward achieving the MHCC's (2012) goal of increasing the availability of safe, affordable housing with supports across the country. 


\section{Limitations}

There are several limitations to this study that must be acknowledged. First, a chain referral sampling approach was used, which yielded a non-random sample. In addition, although efforts were made to generate more participation by service providers in Quebec, representation in the study remained low. A related limitation is that participants self-selected the survey that they perceived to be most applicable to their roles and organizations. Because some housing agencies also deliver mental health services, there may have been some overlap between the roles of service providers. Lastly, the specific roles of the participants (e.g., direct care staff, management, landlord) were unknown. It is possible that perspectives may differ between, and within, provider groups due to their roles.

\section{Conclusion}

Service providers perceive many unmet support needs among people with mental illness and barriers to meeting service users' needs. Supports gaps and barriers related to high support and emergency housing options, integration of mental health and housing services, agency incapacity to provide additional services, and support for people with complex needs were among the most prevalent problems identified by service providers. Differences between housing and community-based mental health service providers were few, indicating a high level of concordance on the areas where more focus and work are required. Overall, the findings from service providers highlight the need for more safe, affordable housing with supports, as well as the development of service partnerships to reduce burden and barriers faced by direct-service providers in addressing the unmet support needs of people with mental illness and helping them to stay stably housed.

\section{REFERENCES}

Aubry, T., Cherner, R., Ecker, J., Jetté, J., Rae, J., Yamin, S., .. McWilliams, N. (2015a). Perceptions of private market landlords who rent to tenants of a housing first program. American Journal of Community Psychology, 55, 292-303. doi:10.1007/s10464-015-9714-2

Aubry, T., Goering, P., Veldhuizen, S., Adair, C. E., Bourque, J., Distasio, J., ... Tsemberis, S. (2016). A multiple-city RCT of housing first with assertive community treatment for homeless Canadians with serious mental illness. Psychiatric Services, 67, 275-281. doi:10.1176/appi.ps.201400587

Aubry, T., Tsemberis, S., Adair, C. E., Veldhuizen, S., Streiner, D., Latimer, E., \& Goering, P. (2015b). One-year outcomes of a randomized controlled trial of housing first with ACT in five Canadian cities. Psychiatric Services, 66, 463-469. doi:10.1176/appi.ps.201400167

Baggett, T. P., O’Connell, J. J., Singer, D. E., \& Rigotti, N. A. (2010). The unmet health care needs of homeless adults: A national study. American Journal of Public Health, 100, 1326-1333. doi:10.2105/ajph.2009.180109

Bengtsson-Tops, A., \& Hansson, L. (2014). Landlords' experiences of housing tenants suffering from severe mental illness: A Swedish empirical study. Community Mental Health Journal, 50, 111-119.

Benjamini, Y., \& Hochberg, Y. (1995). Controlling the false discovery rate: A practical and powerful approach to multiple testing. Journal of the Royal Statistical Society, 57, 289-300.

Canavan, R., Barry, M. M., Matanov, A., Barros, H., Gabor, E., Greacen, T., ... Priebe, S. (2012). Service provision and barriers to care for homeless people with mental health problems across 14 European capital cities. BMC Health Services Research, 12, 1-9. doi:10.1186/1472-6963-12-222

Daiski, I. (2007). Perspectives of homeless people on their health and health needs priorities. Journal of Advanced Nursing, 58, 273-281. doi:10.111/j.1365-2648.2007.04234.x 
Folsom, D. P., Hawthorne, W., Lindamer, L., Gilmer, T., Bailey, A., Golshan, S., ... Jeste, D. V. (2005). Prevalence and risk factors for homelessness and utilization of mental health services among 10,340 patients with serious mental illness in a large public mental health system. American Journal of Psychiatry, 162, 370-376.

Foster, S., LeFauve, C., Kresky-Wolff, M., \& Rickards, L. D. (2010). Services and supports for individuals with cooccurring disorders and long-term homelessness. Journal of Behavioral Health Services \& Research, 37, 239-251. doi:10.1007/s11414-009-9190-2

Gaetz, S., Gulliver, T., \& Richter, T. (2014). The state of homelessness in Canada: 2014. Toronto, Ontario, Canada: Homeless Hub Press.

Gilmer, T. P., Manning, W. G., \& Ettner, S. L. (2009). A cost analysis of San Diego county's REACH program for homeless persons. Psychiatric Services, 60, 445-450.

Gilmer, T. P., Stefancic, A., Ettner, S. L., Manning, W. G., \& Tsemberis, S. (2010). Effect of full-service partnerships on homelessness, use and costs of mental health services, and quality of life among adults with serious mental illness. Archives of General Psychiatry, 67, 645-652. doi:10.1001/archgenpsychiatry.2010.56

Hauff, A. J., \& Secor-Turner, M. (2014). Homeless health needs: Shelter and health service provider perspective. Journal of Community Mental Health Nursing, 31, 103-117. doi:10.1080/07370016.2014.901072

Hwang, S. W. (2000). Mortality among men using homeless shelters in Toronto, Ontario. Journal of the American Medical Association, 283, 2152-2157.

Hwang, S. W. (2001). Homelessness and health. Canadian Medical Association Journal, 164, 229-233.

Hwang, S. W., Chiu, S., Kiss, A., Katic, M., Tolomiczenko, G., Levinson, W., ... Cowan, L. (2005). Use of meal programs and shelters by homeless people in Toronto [Abstract]. Journal of Urban Health, 82, ii45-47.

Kerman, N., Eckerle Curwood, S., Sirohi, R., \& Trainor, J. (2013). What's in the basket of services? Support preferences of mental health consumers and family members. Canadian Journal of Community Mental Health, 32, 43-58. doi:10.7870/cjemh-2013-018

Kloos, B., Townley, G., Chien, V. H., Davis, B. A., Kurzban, L., \& Asiamah, D. (2014). Recovering community in mental health: The contributions and challenges of community psychology. In G. Nelson, B. Kloos, \& J. Ornelas (Eds.), Community psychology and community mental health: Towards transformative change. New York: Oxford University Press.

Kushel, M. B., Evans, J. L., Perry, S., Robertson, M. J., \& Moss, A. R. (2003). No door to lock: Victimization among homeless and marginally housed persons. Archives of Internal Medicine, 163, 2492-2499. doi:10.1001/ archinte.163.20.2492

Lougheed, D. C., \& Farrell, S. (2013). The challenge of a "triple diagnosis": Identifying and serving homeless Canadian adults with a dual diagnosis. Journal of Policy and Practice in Intellectual Disabilities, 10, 230-235. doi:10.1111/ jppi.12041

Lurie, S., \& Goldbloom, D. S. (2015). More for the mind and its legacy. Canadian Journal of Community Mental Health, 34, 7-30. doi:10.7870/cjemh-2015-007

MacLeod, T., Nelson, G., O'Campo, P., Jeyaratnam, J. (2015). The experiences of landlords and clinical and housing service staff in supportive independent housing interventions. Canadian Journal of Community Mental Health, 34, 1-17. doi:10.7870/cjemh-2015-004

Mental Health Commission of Canada. (2012). Changing directions, changing lives: The mental health strategy for Canada. Calgary, Alberta, Canada: Author.

Mental Health Commission of Canada. (2013a). Turning the key: Assessing housing and related supports for persons living with mental health problems and illness. Calgary, Alberta, Canada: Author.

Mental Health Commission of Canada. (2013b). Turning the key: Assessing housing and related supports for persons living with mental health problems and illness-Appendices. Calgary, Alberta, Canada: Author.

Meschede, T. (2011). From street life to housing: Consumer and provider perspectives on service delivery and access to housing. Cityscape, 31, 71-93.

Nelson, G. (2010). Housing for people with serious mental illness: Approaches, evidence, and transformative change. Journal of Sociology and Social Welfare, 37, 123-146.

Nelson, G., Aubry, T., \& Lafrance, A. (2007). A review of the literature on the effectiveness of housing and support, assertive community treatment, and intensive case management interventions for persons with mental illness who have been homeless. American Journal of Orthopsychiatry, 77, 350-361. doi:10.1037/0002-9432.77.3.350 
Nichols, N., \& Doberstein, C. (Eds.). (2016). Exploring effective systems responses to homelessness. Toronto, Ontario, Canada: Homeless Hub Press.

Palepu, A., Patterson, M. L., Moniruzzaman, A., Frankish, J., \& Somers, J. (2013). Housing first improves residential stability in homeless adults with concurrent substance dependence and mental disorders. American Journal of Public Health, 103, 30-36. doi:10.2105/ajph.2013.301628

Rog, D. J., Marshall, T., Dougherty, R. H., George, P., Daniels, A. S., Ghose, S. S., \& Delphin-Rittmon, M. E. (2014). Permanent supportive housing: Assessing the evidence. Psychiatric Services, 65, 287-294. doi:10.1176/appi. ps.201300261

Townley, G., Kloos, B., \& Wright, P. A. (2009). Understanding the experience of place: Expanding methods to conceptualize and measure community integration of persons with serious mental illness. Health \& Place, 15, 520-531. doi:10.1016/j.healthplace.2008.08.011

Tsemberis, S. J. (2010). Housing first: The pathways model to end homelessness for people with mental illness and addiction. Center City, MN: Hazelden.

Woodhall-Melnik, J. R., \& Dunn, J. R. (2016). A systematic review of outcomes associated with participation in housing first programs. Housing Studies, 31, 287-304. doi:10.1080/02673037.2015.1080816

Zippay, A., \& Thompson, A. (2007). Psychiatric housing: Locational patterns and choices. American Journal of Orthopsychiatry, 77, 392-401. doi:10.1037/0002-9432.77.3.392 